\title{
Your Review is Vital to JNEB
}

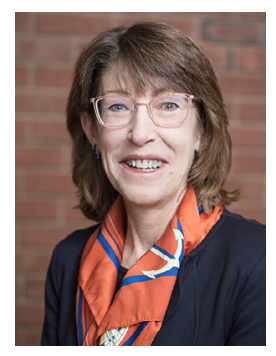

First, I want to sincerely thank our Board of Editors especially, but all our ad hoc reviewers for the time, expertise, and energy they devote to carefully and thoroughly providing suggestions and insights for all the many manuscripts we receive at JNEB! In 2020, we received almost 1,000 manuscripts. While not all of these make it to the reviewer invitation stage, this is still a lot of work. Without your volunteered time, JNEB would not be flourishing as it is.

We try to recognize the diligent work of our reviewers either by invitations to our Board of Editors or through our Reviewer Excellence awards. We try to communicate these achievements not only to the individuals but also to the department heads, as these contributions and recognitions reflect a highly valued scholarship level that is important in promotion and tenure and new position applications.

We also recognize that everyone is busy and tired and in need of some "downtime." To provide a carrot for those who can and do complete reviews for us in the months leading up to the Society's annual conference, we will be randomly selecting from completed reviews each month for a free registration for SNEB's virtual 2021 annual conference!

If you need assistance with signing up to be a reviewer for JNEB, please contact managingeditor@jneb.org. All research articles require reviewers to hold a doctorate or equivalent, but our GEMs (Great Educational Materials) require only an MS or equivalent. If you are signing up as a new reviewer, be sure to select a broad number of classifications that communicate to editors where you feel your expertise is. This will match you as a reviewer to submitted manuscripts that the editors select from.

General guidelines for reviewing can be found at: https://www.jneb. org/content/general-reviewer-guide lines. Reviewer checklists can be found for quantitative papers (https:// www.jneb.org/content/quantitativeguidelines) and qualitative papers (https://www.jneb.org/content/qualita tive-guidelines) because there is so much to remember. These checklists do not need to be submitted with your review but can be helpful as you write your review.
Remember that JNEB uses a double-blind peer review system. This means that the authors are blinded to who the reviewers are, and the reviewers are blinded to who the authors are. Of course, all manuscripts that you might review are confidential. The only exception to this is if you are mentoring a graduate student through a journal review process. In these cases, you may discuss with your student, indicate on the review that it is a mentored review, and both of you hold the content and review as confidential.

Expertise within our scope of research and practice is sometimes a small circle. We often know each other's work, even when we don't see their names. If you have a conflict of interest, either "real" or perceived, please let us know. Any bias towards an author's work or against them should not enter into the peer-review process.

To those of you who say "yes" to reviewer invitations - many thanks! JNEB is your journal, and your experience and expertise show on every page.

Karen Chapman-Novakofski $P h D, R D N$ Editor-in-Chief 